\title{
Psychosocial Impacts of Chronic Kidney Disease and Dialysis Therapy
}

\author{
Elizabeth Adedamola Adeyemi ${ }^{1}$, Yusuff Adebayo Adebisi ${ }^{2}$, Abdulhammed \\ Opeyemi Babatunde ${ }^{3 *}$ \\ ${ }^{1}$ Department of Nursing, Faculty of Clinical Sciences, College of Health Sciences, Osun State University, Osogbo, Osun State, Nigeria. \\ ${ }^{2}$ Faculty of Pharmacy, University of Ibadan, Ibadan, Oyo State, Nigeria. \\ ${ }^{3}$ Department of Medicine and Surgery, Faculty of Clinical Sciences, College of Medicine, University of Ibadan, Ibadan, Oyo State, Nigeria. \\ Received 03 September 2020; Revised 28 February 2021; Accepted 18 March 2021; Published 01 June 2021
}

\begin{abstract}
Background: Chronic Kidney Disease (CKD) has been a significant global health problem and a source of an enormous burden on the healthcare system and psychological distress for diagnosed patients. This study aims to understand the psychosocial impacts of CKD and dialysis therapy on patients undergoing dialysis in LAUTECH Teaching Hospital, Osogbo. Methodology: A descriptive study design was used, and the sampling technique was purposive. Subject participation was voluntary and preceded informed consent. Patients that had CKD and undergoing dialysis were identified. Data were collected, cleaned, and analysed using SPSS Version 23. Results: Patients perceptions of life and social limitations due to CKD and dialysis therapy revealed that $74.1 \%$ of the respondents always feel anxious, $67.8 \%$ feel that adjusting to dialysis is difficult, $85.5 \%$ of the respondents think that CKD and dialysis therapy is making them poorer, $90.3 \%$ feel they were neglecting important activities in life due to dialysis therapy. There was a significant relationship between patients' perception of life and social limitations and the perceived influence of dialysis therapy on family functions and support persons $(\mathrm{p}<0.05)$ as well as the level of income and behavioural compliance. Conclusion: Our study revealed that CKD and dialysis therapy have major psychosocial impacts on the patients although many can cope well. We recommend more financial supports and interventions for CKD patients undergoing dialysis therapy.
\end{abstract}

Keywords: Chronic Kidney Disease; Psychosocial impacts; Patients; Dialysis therapy; LAUTECH Teaching Hospital.

\section{Introduction}

Chronic Kidney Disease (CKD) has been defined as a type of disease, which brings about the gradual loss of kidney function over a range of periods which could be from months or years [1]. It involves kidney deterioration thus causing the kidney to require the use of a mechanism that performs the functions of the kidney outside the endogenous kidney. The psychosocial influences and effects of CKD involve how it affects the patients' quality of life and their relationships with their families, including some major effects that the disease process and its treatment may have on the patients' financial, social, and economical lives. The major causes of CKD are stated to include diabetes, polycystic kidney disease, hypertension (which could be a complication or the major cause of illness), and glomerulonephritis [2]. Their physical health, functional status, personal relationships, social and economic status are usually greatly affected by undergoing dialysis as a major treatment of CKD. Many factors could bring about or cause patients with CKD to be

* Corresponding author: abdulhammedbabatunde99@gmail.com

http://dx.doi.org/10.28991/SciMedJ-2021-0302-5

$>$ This is an open access article under the CC-BY license (https://creativecommons.org/licenses/by/4.0/).

(C) Authors retain all copyrights. 
undergoing psychological stress, these various factors include socio-economic factors which majorly is associated with financial difficulties or crises, and also a temporary or permanent change in the social status of the individual and their marital relationships. Sometimes, these patients may also experience fear of dying, depression due to partial or total dependence on the artificial mechanism of exogenous kidneys. For patients undergoing dialysis, stressors are usually much on them compared to those who are not being treated with dialysis therapy. This is mostly associated with loss of job, persistent weakness, or fatigue because of the disease process, poor family support, and a feeling of low self-esteem due to disturbed body image, associated with weight loss, decreased libido, easily fatigued and frequent hospitalization [3]. Whereas, if all these problems were not present, their functionality psychologically would be optimal.

According to the global burden of disease, CKD was ranked 18th in the list of causes of a total number of global deaths in 2010 [4]. In Nigeria, seven cross-sectional population-based studies were identified, of which two studies made use of the Cockcroft-Gault observed a prevalence of $24.4 \%$ and $26 \%$ [5]. Besides, the other four studies observed a prevalence of $12.3 \%, 14.2 \%$, and 13.4\% using the Modification of Diet in Renal Disease [5]. Also using the CKD epidemiology collaboration equation, $11.4 \%$ was the prevalence while the male to female ratio of CKD were $1: 1.9$, 0.8:1, 1:1.6, 1:2, 1:1.8, 1:1.4 [6]. The risk factors observed were old age, hypertension, diabetes mellitus, and obesity, including a family history of diabetes mellitus and renal diseases, and hypertension [7].

The Global Burden of Disease analysis in 2017 however suggested that the global prevalence of CKD was $9.1 \%$ (697.5 million) in which the average and age-standardized global prevalence was higher in girls and women $(9.5 \%)$ than in men and boys $(7.3 \%)$ when compared [8]. CKD has been a major concern as well as a significant global health problem which had been a source of an enormous burden on the healthcare system as a whole and in turn became a source of distress psychologically to patients. It also often results in various impairments in the cardiovascular system and consequently results in a high rate of morbidity and mortality [9]. Most studies had revealed that generally the prevalence of CKD and dialysis therapy rate in the total world population is unknown and may also vary in different countries as well as geographical regions and continents [10].

Furthermore, dialysis has been known to be the temporary measure applied either in acute kidney trauma or sometimes in cases of people who might need a kidney transplant, however, this is a permanent mode of treatment in people who had been recommended for kidney transplant [11]. There are various forms of dialysis therapy however, this study focuses on haemodialysis which had been stated to be the most common procedure performed in the United States hospitals and was accounted to occur in 909,000 cases of patients who are receiving this therapy [12]. Therefore, the treatment recommended, and perceptions of illness usually were formed as a function and result of various types of treatment available for CKD [13]. For CKD to occur, the better and larger portion of the total nephron must have become damaged, thus causing the CKD process and pathology to progress irrespective of its etiology. Tsai et al. (2012) [14] stated that initially, hyper-filtration in the nephron causes the Renin- Angiotensin Aldosterone System (RAAS) to induce proteinuria, thus progressively causing the protein uptake to result in the fibrosis of the glomerulus and nearby tubule and consequently results in a gradual and progressive decline in the Glomerular Filtration Rate (GFR).

Hemodialysis does have a serious psychological impact upon patients suffering from CKD because usually majority of patients with CKD would require replacement treatments including hemodialysis, peritoneal dialysis, and kidney transplantation. A study carried out at Leady Reading Hospital Peshawar revealed that depression and anxiety were more prevalent in male while female shows a poor quality of life as compared to male [15]. Hemodialysis, however, could comprise various categories of complex treatments for CKD patients which require numerous visits to the hospital or dialysis center per week thus causing a significant effect in the patients' routine life.Getting an effective social connection is essential and of great benefit to CKD sufferers as these social connections could positively affect their health and wellbeing. Usually, patients that have effective social connection can handle and deal with their anxiety, stress, and psychological upset in a better way and also experience improved well-being outcome [16] thus to get a substantial well-being outcome, it is essential and paramount to improve social support of family and significant others [17].

The prevalence of depression in patients with CKD is usually higher compared to the general population due to various reasons such as inability to perform socially as much as they used to do [18]. Usually, the life of a CKD sufferer undergoing dialysis could become reorganized and adapted to changes resulting from the illness pathology and its mode of management which may also affect their quality of life [18]. A study carried out in Morocco showed that anxiety disorders $(25.2 \%)$, social phobia at $9.7 \%$, and panic disorder at $7.8 \%$ were common amongst CKD patients that were undergoing dialysis which could be associated with uremic symptoms.

A cohort study conducted by $\mathrm{Ng}$ et al. [19] reported that $39.6 \%$ of patients undergoing dialysis treatment have depression and $31.8 \%$ had anxiety. Thus, it is pertinent to know that health-related quality of life is an essential cultural concept as revealed by the difference in the association between clinical outcomes such as patient compliance to therapy or patient survival [20]. A study reported that CKD patients with elevated depression and anxiety may perceive less social support from family and significant others [21]. 
However, despite the relationship between CKD treatment through dialysis therapy and the mental well-being of patients, there has been no study in sub-Saharan Africa to elucidate this relationship. Therefore, this study is important to assess the psychological impacts of CKD and dialysis therapy on patients undergoing dialysis in a Nigerian hospital and also elucidate some various coping strategies to maintain healthy mental well-being while undergoing dialysis.

\section{Material and Methods}

A descriptive design was used to carry this study out at Ladoke Akintola University Teaching Hospital; Osogbo (LAUTECH). The study was done using a purposive sampling technique. (See Figure 1) Therefore, all patients with CKD and undergoing dialysis therapy as well as patients that have gone through dialysis before in medical wards, dialysis unit, and medical clinic for out-patients in the facility were included. A letter of permission and introduction was written to the facility to ensure the administration of the questionnaire to the subjects.

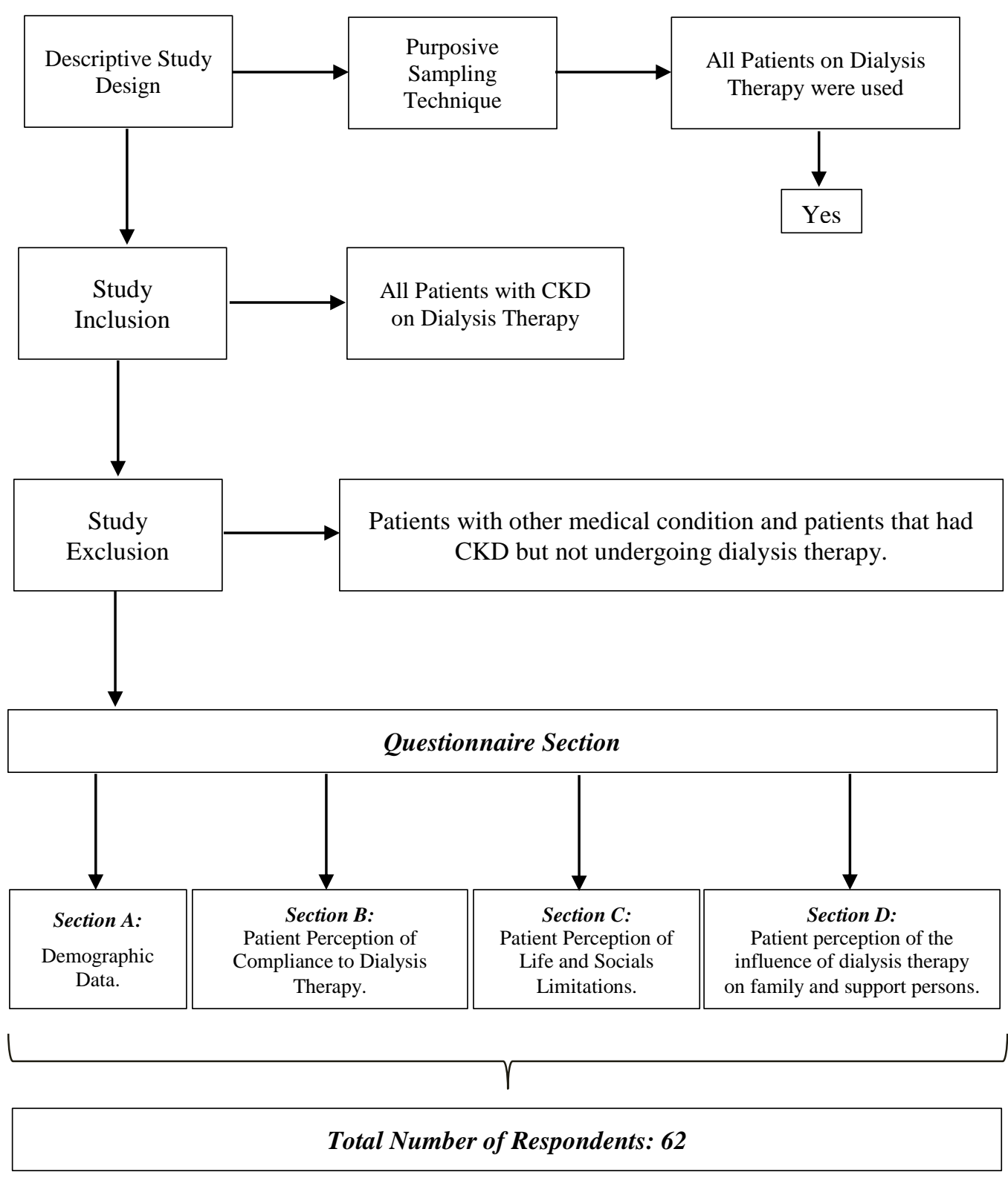

Figure 1. Flowchart illustration on research methodology

Study inclusion criteria were patients that had CKD and undergoing dialysis at the facility while the study excluded CKD patients that were not undergoing dialysis therapy. For this work, the instrument of data collection used was the researcher's self-designed questionnaire. The questionnaires that were administered consisted of four sections A, B, C, and D. In which Section A dealt with the "demographics data" of the respondents with 9(nine) close-ended items in all. Section B dealt with "the patient perception of compliance to dialysis therapy" with fourteen (14) close-ended items in which, 'strongly agreed and agreed' responses were scored 1 for a correct statement while 'strongly disagreed and disagreed' were scored 0 , and vice versa when the statement is to have disagreed and strongly disagreed for all variables of patients' perception of compliance to dialysis therapy. Section $\mathrm{C}$ however, deals with "patient perception of life and 
social limitations due to CKD and dialysis therapy" with eleven (11) close-ended items in which "strongly agree and agree' responses were scored 1 for true statement otherwise scored 0 and vice versa when the statement is to have disagreed or strongly disagreed for all variables of patient perception of life and social limitations due to CKD and dialysis therapy. Finally, Section D consists of the "patient perception of the influence of dialysis therapy on family and support persons" with thirteen (13) close-ended items.

Subject participation was voluntarily following verbal and informed consent. Both genders were recruited to participate in the study and thus the questionnaires were administered to the respondents by the research team. Total subject participation was 62 (male and female, age range; 20-50 years) in which questionnaires were administered for four consecutive weeks to 68 respondents; however, the total of 6 questionnaires was not appropriately answered. The subject's emotions and gestures were greatly observed during questionnaire question interpretation for older patients and unlettered patients to associate their answers with their expressions. Demographic data and other cogent variables in the questionnaires were described using descriptive analysis. The questionnaires were collated and coded thus were analysed using descriptive statistics while the generated hypothesis was analysed using Pearson's Chi-square.

\subsection{Statistical Analyses}

The hypotheses were tested and thus revealed that there was a significant relationship between patients' perception of life and social limitations and perceived influence of dialysis therapy on family functions and support persons using Pearson's Chi-square $(\mathrm{p}<0.05)$. Relationship between influence of socio-demographic variables and their perception of life and social limitations due to CKD and dialysis therapy and there was a significant relationship $(\mathrm{p}<0.05)$.

\section{Results}

The study assessed the psychosocial impacts of CKD and dialysis therapy on patients undergoing dialysis in LAUTECH Teaching Hospital, Osogbo. Table 1 revealed that the socio-demographic characteristics of respondents in which the mean age (in years) of the respondent was found to be $46 \pm 16.1$ with majority (33.9\%) in the >50 range and others were $41-50(25.8 \%), 31-40(22.6 \%), 20-30(12.9 \%)$ and $<20(4.8 \%)$. Larger percentages of the respondents were males (53.2\%). Majority (62.9\%) of the respondents were married. $77.4 \%$ of them were Yoruba. Majority (43.5\%) were civil servant. $24.2 \%$ of the respondents earned more than N100,000 per month, $21.0 \%$ earns between N60,000 - 100,000 and $54.8 \%$ earns less than N60,000. 43.5\% respondents had been on dialysis for 1-6 months while $40.3 \%$ had been taking this therapy for more than 12 months. $58.1 \%$ of respondents undergoes dialysis $1-2$ times per week.

Table 1. Socio-Demographic Characteristics of Respondents

\begin{tabular}{|c|c|c|}
\hline Variable & Frequency $(n=62)$ & Percentage (\%) \\
\hline \multicolumn{3}{|l|}{ Age in years } \\
\hline Mean age \pm SD & $46 \pm 16.1$ & \\
\hline$<20$ & 3 & 4.8 \\
\hline $20-30$ & 8 & 12.9 \\
\hline $31-40$ & 14 & 22.6 \\
\hline $41-50$ & 16 & 25.8 \\
\hline$>50$ & 21 & 33.9 \\
\hline \multicolumn{3}{|l|}{ Sex } \\
\hline Female & 29 & 46.8 \\
\hline Male & 33 & 53.2 \\
\hline \multicolumn{3}{|l|}{ Marital Status } \\
\hline Single & 11 & 17.7 \\
\hline Married & 39 & 62.9 \\
\hline Divorced & - & - \\
\hline Widow & 12 & 19.4 \\
\hline \multicolumn{3}{|l|}{ Ethnicity } \\
\hline Yoruba & 48 & 77.4 \\
\hline Hausa & 4 & 16.1 \\
\hline Igbo & 10 & 6.5 \\
\hline \multicolumn{3}{|l|}{ Occupation } \\
\hline Trader & 20 & 32.3 \\
\hline Civil servant & 27 & 43.5 \\
\hline Artisan & 5 & 8.1 \\
\hline Student & 6 & 9.7 \\
\hline Retired & 4 & 6.5 \\
\hline
\end{tabular}

Monthly income 


\begin{tabular}{lll} 
N100,000-N50,000 & 13 & 21.0 \\
N60,000-N100,000 & 15 & 24.2 \\
N>100,000 & 34 & 54.8 \\
Duration of illness & & \\
$\quad$ 1-6 months & 15 & 24.2 \\
7-12 months & 15 & 24.2 \\
$\quad>12$ months & 32 & 51.6 \\
Duration of dialysis & & \\
1-6 months & 27 & 43.5 \\
7-12 months & 10 & 16.1 \\
$\quad>12$ months & 25 & 40.3 \\
Number of dialysis per week & & \\
1-2 times & 36 & 58.1 \\
$\quad>2$ times & 26 & 41.9 \\
\hline
\end{tabular}

Table 2 and Figure 2 showed patients' perceptions of compliance to dialysis therapy. 14.6\% of the respondents often missed dialysis session while $51 \%$ missed dialysis sometimes, $14.5 \%$ missed dialysis session rarely and $19.4 \%$ of the respondents had never missed dialysis session. $8.1 \%$ of them often took alcohol, $21.0 \%$ took alcohol sometimes, $29.0 \%$ rarely took alcohol while $41.9 \%$ of the respondents never took alcohol.14.5\% always took foods classified as proteins, $22.6 \%$ took it often, $40.3 \%$ did sometimes, $19.4 \%$ took it rarely and $3.2 \%$ did not. $45.2 \%$ adhered to medication regimen always, $37.1 \%$ adhered often, $14.5 \%$ sometimes and $3.2 \%$ rarely. $50 \%$ of them often felt bad about taking medications/drugs, $25.8 \%$ of them often missed follow up appointment, $75.8 \%$ of them did go for follow up appointment, $29 \%$ of them ate at restaurants often, $27.5 \%$ still take a reasonable amount of salts, only $33.8 \%$ of them often measured the amount of water take daily and $33.9 \%$ often measured their weight daily.

Table 2. Patients perceptions of compliance to dialysis therapy $(n=62)$

\begin{tabular}{lccccc}
\hline \multicolumn{1}{c}{ Variable } & Always $n(\%)$ & Often $n(\%)$ & Sometimes $n(\%)$ & Rarely $n(\%)$ & Never $n(\%)$ \\
\hline Miss dialysis session & $5(8.1)$ & $4(6.5)$ & $32(51.6)$ & $9(14.5)$ & $12(19.4)$ \\
Take alcohol & - & $5(8.1)$ & $13(21.0)$ & $18(29.0)$ & $26(41.9)$ \\
Take foods classified as proteins & $9(14.5)$ & $14(22.6)$ & $25(40.3)$ & $12(19.4)$ & $2(3.2)$ \\
Adhere to taking medications/drugs & $28(45.2)$ & $23(37.1)$ & $9(14.5)$ & - & $2(3.2)$ \\
Feel bad about taking medications/drugs & $27(43.5)$ & $4(6.5)$ & $13(21.0)$ & $16(25.8)$ & $2(3.2)$ \\
Miss follow up appointment & $10(16.1)$ & $6(9.7)$ & $29(46.8)$ & $6(9.7)$ & $11(17.7)$ \\
Come for follow up appointment & $19(30.6)$ & $28(45.2)$ & $9(14.5)$ & $4(6.5)$ & $2(3.2)$ \\
Eat at restaurants & $10(16.1)$ & $8(12.9)$ & $16(25.8)$ & $10(16.1)$ & $18(29.0)$ \\
Still take a reasonable amount of salts & $13(21.0)$ & $4(6.5)$ & $15(24.2)$ & $23(37.1)$ & $7(11.3)$ \\
Measure the amount of water take daily & $10(16.1)$ & $11(17.7)$ & $29(46.8)$ & $12(19.4)$ & - \\
Measure weight daily & $6(9.7)$ & $15(24.2)$ & $31(50.0)$ & $10(16.1)$ & - \\
\hline
\end{tabular}

Figure 2 showed that $32(51.6 \%)$ of the respondents has positive perception towards behavioural compliance to dialysis therapy and $30(48.4 \%)$ has negative perception.

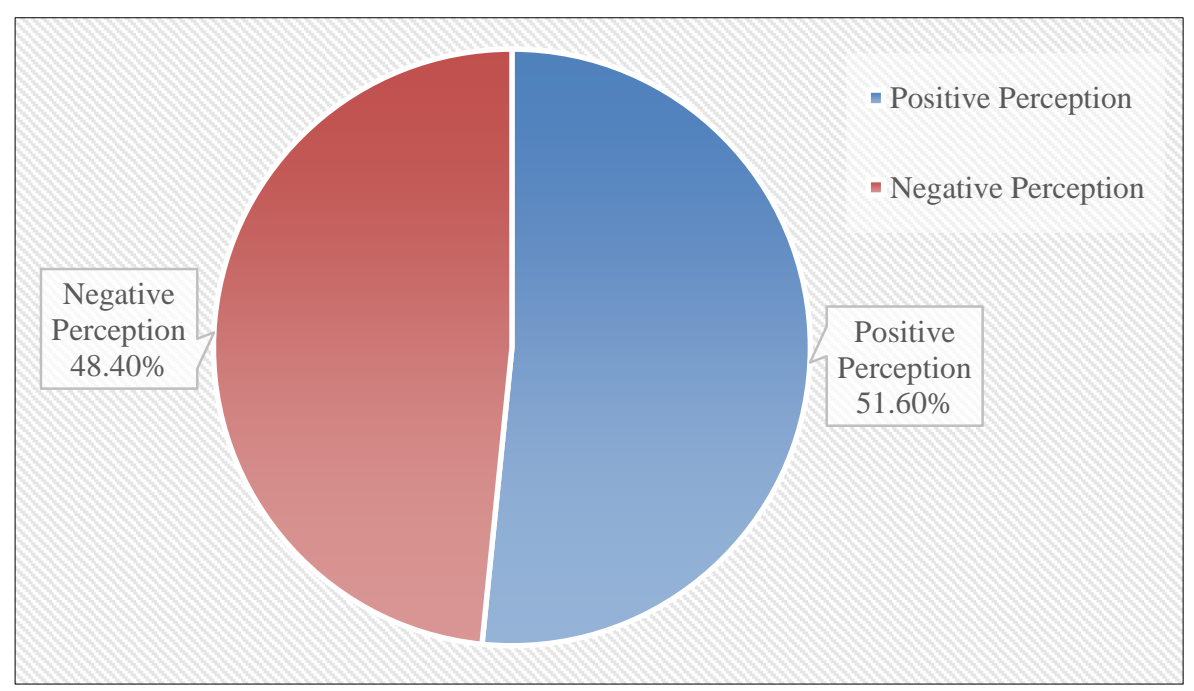

Figure 2. Patients' perceptions of compliance to dialysis therapy 
Table 3 and Figure 3 showed patients perceptions of life and social limitations due to CKD and dialysis therapy and $74.1 \%$ of the respondents believed that they feel anxious always, $53.5 \%$ believed that they adjust well to dialysis, $67.8 \%$ of them felt that adjusting to dialysis is difficult, $85.5 \%$ of the respondents think that CKD and dialysis therapy is making them poorer, $90.3 \%$ felt that they were neglecting important activities in life due to dialysis therapy, $77.4 \%$ of them did not eat anything they felt like taking anymore, $69.4 \%$ of the respondents felt dependent on the dialysis machine and health care providers, $50 \%$ of the respondents agreed that they did not have personal control on self anymore due to CKD and dialysis, $54.9 \%$ of them believed that they still have personal control on self despite being on dialysis and $73.2 \%$ of them accept the dialysis as a substantial method of living with CKD.

Table 3. Patients perceptions life and social limitations due to CKD and dialysis therapy (n=62)

\begin{tabular}{|c|c|c|c|c|}
\hline Variable & A $n(\%)$ & SA $n(\%)$ & $\mathbf{D} n(\%)$ & SD $n(\%)$ \\
\hline Feel adjust to dialysis is difficult & $22(35.5)$ & $20(32.3)$ & $20(32.3)$ & - \\
\hline Think CKD and dialysis therapy are making me poorer & $16(25.8)$ & $37(59.7)$ & $2(3.2)$ & $7(11.3)$ \\
\hline Do not eat anything feel like taking anymore & $14(22.6)$ & $34(54.8)$ & $6(9.7)$ & $8(12.9)$ \\
\hline Feel dependent on the dialysis machine and health care providers & $20(32.3)$ & $23(37.1)$ & 13(21.0) & $6(9.7)$ \\
\hline Feel do not have personal control on self anymore due to CKD and dialysis & 13(21.0) & $18(29.0)$ & $28(45.2)$ & $3(4.8)$ \\
\hline
\end{tabular}

Figure 3 shows that $33(51.7 \%)$ of the respondents has positive perceptions on life and social limitations due to CKD and dialysis therapy while $29(48.3 \%$ ) of them has negative perception.

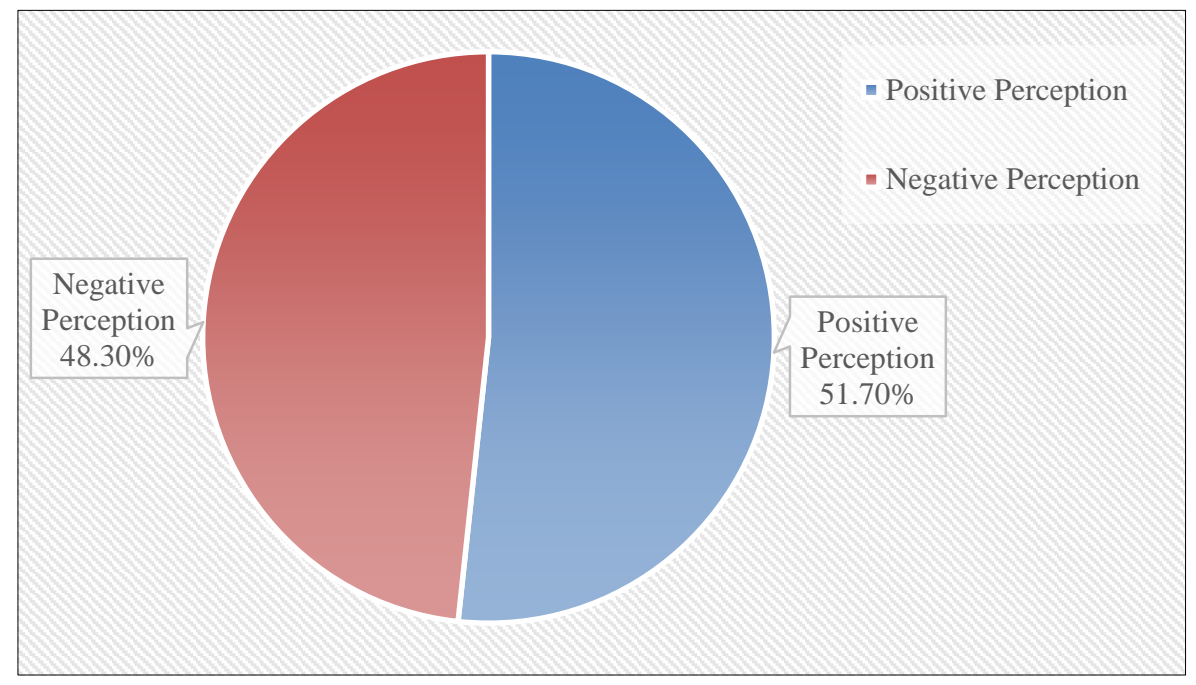

Figure 3. Patients' perceptions life and social limitations due to CKD and dialysis therapy

Table 4 showed a significant relationship between patients' perception of life and social limitations and perceived influence of dialysis therapy on family functions and support persons $(\mathrm{p}<0.05)$.

Table 4. Relationship between patient perception of life and social limitations and perceived influence of dialysis therapy on family functions and support persons

\begin{tabular}{|c|c|c|c|c|c|}
\hline \multirow[b]{2}{*}{ Variables } & \multicolumn{5}{|c|}{ Patient perception of life and social limitation } \\
\hline & $\begin{array}{l}\text { Positive } \\
\text { n }(\%)\end{array}$ & $\begin{array}{l}\text { Negative } \\
\text { n }(\%)\end{array}$ & $\begin{array}{c}\text { Pearson } \\
\text { Chi-square }\end{array}$ & $\begin{array}{c}\text { Degree of } \\
\text { Freedom }\left(D_{f}\right)\end{array}$ & $\begin{array}{l}P \text {-value } \\
\text { (P) }\end{array}$ \\
\hline $\begin{array}{l}\text { Influence of dialysis therapy on family } \\
\text { functions and support persons: }\end{array}$ & & & 13.05 & 1 & $<0.001 *$ \\
\hline Positive & $19(30.6)$ & $23(37.1)$ & & & \\
\hline Negative & $0(0.0)$ & $20(32.3)$ & & & \\
\hline
\end{tabular}




\section{Discussion}

The study assessed the psychosocial impacts of CKD and dialysis therapy on patients undergoing dialysis in LAUTECH Teaching Hospital Osogbo. The study revealed and indicated that most of the respondents usually experience anxiety and have a high chance of getting exposed to psychological stressors usually due to maladjustment in dialysis which could be reduced if intervention is done early. This is consistent with a research study carried out by Anees et al. (2011) [13]. The study revealed that most of the respondence were male (53.2\%), thus suggesting that CKD is more prevalent in men than women which is supported by and that CKD occurs mostly in men which are supported by an Australian study where 148 men of 244 participants were undergoing hemodialysis and have CKD [5]. Another study that investigated gender role in the quality of life, depression and anxiety in CKD sufferer concluded that depression and anxiety are more prevalent in male while female shows the poor quality of life as compared to male [15] in which own study concluded that CKD is more prevalent in the male gender.

The study further revealed that more than the average percentage of the respondents had a positive perception of compliance to dialysis therapy as they were dependent on dialysis as the only chance at living. Also, the mean age of the respondents was $46 \pm 16.1$ with the majority being between age 41 and 50 years old, thus showing that older or advanced age could affect the occurrence of CKD as well as the quality of life as the disease progresses. This was in consistence with a study carried out by [5] thus accounting for their low quality of life which in contrast with another study, it was stated that younger patients $(<30$ years) usually have a significantly better quality of life and less aggravating symptoms, which could be because of the short duration of disease, and minor complications [22]. According to another study, older age was stated and acknowledged to be the most important predictor of lower QOL and health status among patients undergoing dialysis [23].

It was observed that respondents believed they adjusted well to dialysis therapy as this was believed to possible due to the presence of a strong social network and supporting relatives which are in line with a study conducted by Lilympaki et al. (2016) [21] who reported that CKD patient with elevated depression and anxiety may perceive less social support from family and significant others and in contrast, this was supported by another study which suggests that prolong dialysis treatment causes negative effects on the CKD patients. The study further concludes that to get substantial treatment outcomes, it is essential and imperative to improve the social support of family and significant others [24]. A greater percentage affirmed that dialysis therapy makes them poorer which could be affiliated with low financial income and quality of life and thus some could not afford dialysis therapy and they also neglect major and important activities in life which are consistent with a cross-sectional study conducted among 150 patients with CKD and understanding hemodialysis in two major centers in Nepal which conclude that patients that have CKD and undergoing dialysis have an overall low quality of life.

A cohort study conducted by $\mathrm{Ng}$ et al. [19] reported that $39.6 \%$ of patients undergoing dialysis treatment have depression and $31.8 \%$ had anxiety which is in line with their study which concluded that patients undergoing dialysis experience a greater level of anxiety, distress, and psychological problems. More than half of the respondents had positive perceptions of life and social limitations due to CKD and dialysis therapy. Hinkle \& Cheever (2013) [12] stated that it ultimately affects their social, economic, and psychological well-being negatively. Other respondents had a negative perception of life and social limitations due to CKD and dialysis therapy which is in line with Anees et al. (2011) [13] who stated that there is mal-adjustment of patients to dialysis which is usually associated with loss of employment.

This study thereby implies that more interventions should be put in place to assist those that have financial inability to be able to cope and meet up with managing CKD and dialysis therapy. It also suggests that health caregivers and providers should improve in the encouragement of patients on adherence to taking their medications and efficient attendance for dialysis sessions as well as the emphasis on early management and treatment of CKD by creating awareness about the causes, early symptoms, and psychosocial impacts on individuals and families in the society. And lastly, the study suggests that the government should also participate in the care of people undergoing dialysis therapy through the provision of special care packages related to hemodialysis.

\subsection{Limitations}

This study only justifies the psychosocial impacts of CKD and dialysis therapy amongst patients that had undergone dialysis and those undergoing dialysis therapy at LAUTECH Teaching hospital, Osogbo. Due to small sample size, findings cannot be used to generalize for the whole nation. Other limitations of the study include refusal of some patients to give consent, research funding and difficulty to obtain ethical consideration of the research setting.

\section{Conclusion}

This study thus concluded that patients with CKD and undergoing dialysis are more exposed to psychosocial stress which could thus directly or indirectly affect their quality of life. Based on the findings from this study, the following recommendations are deemed important and necessary. 
More interventions should be put in place to assist those who are financially incapacitated to be able to meet up with managing CKD and dialysis therapy. Health care givers should improve in the encouragement of patients on the adherence to taking medications and efficient attendance for dialysis sessions. Health care givers should also emphasize in the society about the early management and treatment of CKD by creating awareness about the causes, early symptoms and psychosocial impacts on individuals and families. Lastly, the government should also participate in the care of people undergoing dialysis therapy through provision of special care packages relating to hemodialysis.

\section{Declarations}

\subsection{Author Contributions}

E.A.A. conceived the research idea and study design; Y.A.A. was involved in planning and supervision of the work; E.A.A. was involved in data acquisition and writing first draft; A.O.B. was involved in drafting final manuscript and designed the tables; Y.A.A. and A.O.B. performed the final critical revisions. All authors have read and agreed to the published version of the manuscript.

\subsection{Funding}

The authors received no financial support for the research, authorship, and/or publication of this article.

\subsection{Ethical Approval}

The study protocol was approved by the Ethics Committee of Osun State University and the interview content was described to respondents, and an informed verbal consent was obtained before the start of the interview.

\subsection{Data Availability Statement}

The data presented in this study are available in article.

\subsection{Conflict of Interest}

The authors declare that they have no known competing financial interests or personal relationships that could have appeared to influence the work reported in this paper.

\section{References}

[1] What is chronic kidney disease? National institute of diabetes and digestive and kidney disease. (2017). Available Online: https://www.niddk.nih.gov/health-information/kidney-disease/chronic-kidney-disease-ckd/what-is-chronic-kidney-disease. (accessed on 4 April 2021).

[2] Papadakis, E. (2010). Approach of patients with kidney disease and patients with betathalassemia in a general hospital in crete and investigation of their quality of life. Thesis. Available Online: https://mph.med.uoc.gr/files/Dissertations/ Papadakis\%20Evag_2010.pdf (accessed on 4 April 2021).

[3] Theofilou, P.A. (2011). Sexual functioning in chronic kidney disease: the association with depression and anxiety. Hemodialysis International. 16(1):76-81. doi:10.1111/j.1542-4758.2011.00585.x.

[4] Lozano, R., Naghavi, M., Foreman, K., Lim, S., Shibuya, K., Aboyans, V., Abraham, J., Adair, T., Aggarwal, R., Ahn, S. Y., Alvarado, M., Anderson, H. R., Anderson, L. M., Andrews, K. G., Atkinson, C., Baddour, L. M., Barker-Collo, S., Bartels, D. H., Bell, M. L., Benjamin, E. J., ... \& Memish, Z. A. (2012). Global and regional mortality from 235 causes of death for 20 age groups in 1990 and 2010: a systematic analysis for the Global Burden of Disease Study 2010. Lancet (London, England), 380(9859), 2095-2128. doi:10.1016/S0140-6736(12)61728-0.

[5] Chukwuonye, I. I., Ogah, O., Anyabolu, E., Ohagwu, K., Nwabuko, O. C., Onwuchekwa, U., ... Oviasu, E. (2018). Prevalence of chronic kidney disease in Nigeria: systematic review of population-based studies. International Journal of Nephrology and Renovascular Disease, Volume 11, 165-172. doi:10.2147/ijnrd.s162230.

[6] Bikbov, B., Purcell, C. A., Levey, A. S., Smith, M., Abdoli, A., Abebe, M., ... Agudelo-Botero, M. (2020). Global, regional, and national burden of chronic kidney disease, 1990-2017: a systematic analysis for the Global Burden of Disease Study 2017. The Lancet, 395(10225), 709-733. doi:10.1016/s0140-6736(20)30045-3.

[7] Khalil, A., Frazier, K., Lennie, T., \& Sawaya, P. (2011). Depression symptoms and dietary adherence in patients with end stage renal disease. Journal of Renal Care. 37(1):30-39. doi: 10.1111/j.1755-6686.2011.00202.x.

[8] Bakris, G., \& Ritz, E. (2009) Hypertension and kidney disease; a marriage that should be prevented. Hong Kong Journal of Nephrology. 11(1):1-4. doi:10.1016/S1561-5413(09)60001-6.

[9] Pendse, S., Singh, A., \& Zawada, E. (2008). Initiation of dialysis. Handbook of Dialysis. 4th ed. New York, NY, 14-21. 
[10] Ptfuntner, A., Wier, L.M, \& Stock, C. (2013) Most frequent procedures performed in U.S hospital, 2011. HCUP; statistical October 2013. Agency for health care research and quality, Rockville M.D. Available Online: http://www.hcupus.ahrq.gov/reports/statbriefs/sb165.pdf (accessed on 4 April 2021).

[11] Griva, K., Jayasena, D., Davenport, A., Harrison, M., \& Newman, S. P. (2009). Illness and treatment cognitions and health related quality of life in end stage renal disease. British Journal of Health Psychology, 14(1), 17-34. doi:10.1348/135910708x292355.

[12] Hinkle, J. L., \& Cheever, K. H. (2013). Clinical handbook for Brunner \& Suddarth's textbook of medical-surgical nursing. Lippincott Williams \& Wilkins.

[13] Anees, M., Hameed, F., Mumtaz, A., Ibrahim, M., \& Saeed, K. M. (2011). Dialysis-related factors affecting quality of life in patients on hemodialysis. 2011; 5(1): 9-14.

[14] Tsai, Y.-C., Chiu, Y.-W., Hung, C.-C., Hwang, S.-J., Tsai, J.-C., Wang, S.-L., ... Chen, H.-C. (2012). Association of Symptoms of Depression with Progression of CKD. American Journal of Kidney Diseases, 60(1), 54-61. doi:10.1053/j.ajkd.2012.02.325.

[15] Kalsoom, U. (2019). Gender role in anxiety, depression and quality of life in chronic kidney disease patients. Pakistan Journal of Medical Sciences, 36(2). doi:10.12669/pjms.36.2.869.

[16] Santhi S, A., Samson, R., Srikanth, \& D, P. (2018). Effectiveness of physical activity on depression, anxiety, stress and quality of life of patients on hemodialysis. Biomedical Research, 29(9). doi:10.4066/biomedicalresearch.29-18-177.

[17] Ibahim, N., Mohamed, P.A.R., Teo, S., Din, C.N., Halim, A., Gafor, A., \& Ismail, R. (2016) Association between health related quality of life and psychological distress at different stages of chronic kidney disease. Sains Malaysiana. 45(5) 753-759.

[18] Oneib, B., El Filali, A., Bentata, Y., \& Ada, N. (2017). Depression and anxiety disorders in chronic hemodialysis patients and their quality of life: A cross-sectional study about 106 cases in the northeast of morocco. Saudi Journal of Kidney Diseases and Transplantation, 28(2), 341. doi:10.4103/1319-2442.202785.

[19] Ng, H. J., Tan, W. J., Mooppil, N., Newman, S., \& Griva, K. (2014). Prevalence and patterns of depression and anxiety in hemodialysis patients: A 12-month prospective study on incident and prevalent populations. British Journal of Health Psychology, 20(2), 374-395. doi:10.1111/bjhp.12106.

[20] Saad, M., El-Douaihy, Y., Moussaly, E., Rondla, C., Boumitri, C., Daoud, M., \& El Sayegh, S. (2015). Predictors of quality of life in patients with end-stage renal disease on hemodialysis. International Journal of Nephrology and Renovascular Disease, 119. doi:10.2147/ijnrd.s84929.

[21] Lilympaki, I., Makri, A., Vlantousi, K., Koutelekos, I., Babatsikou, F., \& Polikandrioti, ... (2016). Effect of Perceived Social Support on the Levels of Anxiety and Depression of Hemodialysis Patients. Materia Socio Medica, $28(5), 361$. doi:10.5455/msm.2016.28.361-365.

[22] Zyoud, S. H., Al-Jabi, S. W., Sweileh, W. M., Arandi, D. A., Dabeek, S. A., Esawi, H. H., ... Awang, R. (2015). Relationship of treatment satisfaction to health-related quality of life among Palestinian patients with type 2 diabetes mellitus: Findings from a cross-sectional study. Journal of Clinical \& Translational Endocrinology, 2(2), 66-71. doi:10.1016/j.jcte.2015.03.002.

[23] Saffari, M., Pakpour, A. H., Naderi, M. K., Koenig, H. G., Baldacchino, D. R., \& Piper, C. N. (2013). Spiritual coping, religiosity and quality of life: A study on Muslim patients undergoing haemodialysis. Nephrology, 18(4), 269-275. doi:10.1111/nep.12041.

[24] Unsal Avdal, E., Ayvaz, İ., Özgursoy Uran, B. N., Yildirim, J. G., Sofulu, F., \& Pamuk, G. (2020). Opinions of hemodialysis and peritoneum patients regarding depression and psychological problems which they experience: A qualitative study. Journal of Infection and Public Health, 13(12), 1988-1992. doi:10.1016/j.jiph.2020.02.041. 